\title{
Examining Patterns of Polypharmacy in Bipolar Disorder: Findings from the REAP-BD, Korea
}

\author{
Kiwon Kim¹, Hyunju Yang ${ }^{2}$, Euihyeon $\mathrm{Na}^{3}$, Hoseon Lee ${ }^{4}$, Ok-Jin Jang ${ }^{5}$, Hyung-Jun Yoon ${ }^{6}$, \\ Hong Seok Oh ${ }^{7}$, Byung-Joo Ham ${ }^{8}$, Seon-Cheol Park ${ }^{\circledR}$, Shih-Ku Lin ${ }^{10}$, \\ Chay Hoon Tan ${ }^{11}$, Naotaka Shinfuku ${ }^{12}$, and Yong Chon Park ${ }^{4}$ \\ 1'Department of Psychiatry, Veteran Health Service Medical Center, Seoul, Republic of Korea \\ ${ }^{2}$ Department of Psychiatry, Jeju National University, Jeju, Republic of Korea \\ ${ }^{3}$ Department of Psychiatry, Incheon Chamsarang Hospital, Incheon, Republic of Korea \\ ${ }^{4}$ Department of Neuropsychiatry, Hanyang University Guri Hospital, Guri, Republic of Korea \\ ${ }^{5}$ Department of Psychiatry, Bugok National Hospital, Changyeong, Republic of Korea \\ ${ }^{6}$ Department of Psychiatry, Chosun University Hosptial, Gwangju, Republic of Korea \\ ${ }^{7}$ Department of Psychiatry, Konyang University Hospital, Daejeon, Republic of Korea \\ ${ }^{8}$ Department of Psychiatry, Korea University Anam Hospital, Seoul, Republic of Korea \\ ${ }^{9}$ Department of Psychiatry, Inje University Haeundae Paik Hospital, Busan, Republic of Korea \\ ${ }^{10}$ Psychiatric Center, Taipei City Hospital, Taipei, Taiwan \\ ${ }^{11}$ Department of Pharmacology, National University Hospital, Singapore, Singapore \\ ${ }^{12}$ Department of Social Welfare, School of Human Sciences, Seinan Gakuin University, Fukuoka, Japan
}

Based on Korean data from the Research on Asian Psychotropic Prescription Pattern for Bipolar Disorder, this study tried to present prescription patterns in biopolar disorder (BD) and its associated clinical features. Based on the information obtained from the study with structured questions, the tendency of prescription pattern was studied and analyzed. Polypharmacy was predominant, including simple polypharmacy in $51.1 \%$ and complex polypharmacy in $34.2 \%$ of patients. Subjects associated with simple or complex polypharmacy were significantly younger, had higher inpatient settings, a larger portion of onset with manic episode, a shorter duration of untreated illness, a shorter duration of current episode, were more overweight, used less antidepressants and used more anxiolytics. These findings can suggest higher polypharmacy rate in more severe $\mathrm{BD}$ and highlight the necessity of monitoring the weight of subjects with polypharmacy.

Psychiatry Investig 2019;16(5):397-402

Key Words Polypharmacy, Bipolar disorder, Inpatient, Antidepressant.

\section{INTRODUCTION}

Bipolar disorder (BD) is a serious recurrent disorder, presenting as fluctuating mood and energy levels. It is the sixth most common burdensome disorder in the world. ${ }^{1}$ Symptom severity differs greatly between individuals in terms of the duration of current episodes, the number of episodes, functional recovery after remission and the pattern of polarity. All of

\section{Received: November 20, 2018 Revised: February 14, 2019} Accepted: February 26, 2019

$\triangle$ Correspondence: Seon-Cheol Park, MD

Department of Psychiatry, Inje University Haeundae Paik Hospital, 875 Haeundaero, Haeundae-gu, Busan 48108, Republic of Korea

Tel: +82-51-797-3300, Fax: +82-51-797-0298,

E-mail: cogito-ergo-sum@hanmail.net

(c) This is an Open Access article distributed under the terms of the Creative Commons Attribution Non-Commercial License (https://creativecommons.org/licenses/bync/4.0) which permits unrestricted non-commercial use, distribution, and reproduction in any medium, provided the original work is properly cited. which contribute to the level of burden. ${ }^{2-4}$ The complexity of BD's manifestation often makes treatment multifaceted and challenging to clinicians and while numerous clinical guidelines have been developed for the treatment. ${ }^{5-8}$ The application of these guidelines in real world practice is poor, with complications occurring from differences in clinician's preference. Moreover, a wide spectrum of pharmacological regimens in $\mathrm{BD}$ can be attributed to sociocultural factors, ethnicity and insurance status. ${ }^{910}$

Considering the increased prescription of multiple psychotropics in BD patients, bringing adverse side effects, poor drug compliance, and drug interactions, ${ }^{11,12}$ thorough investigation on prescription patterns in $\mathrm{BD}$ is necessary. The Research on Asian Psychotropic Prescription Pattern for Bipolar Disorder (REAP-BD) study would be of benefit to this investigation, due to its large sample size and large number of participating 
countries. Therefore, in this study, Korean data from the REAPBD study is assessed in order to delineate polypharmacy prescription for Koreans with BD and related clinical features.

\section{METHODS}

Sixteen Asian countries and regions, including Bangladesh, China, Hong Kong, India, Indonesia, Japan, Korea, Malaysia, Myanmar, Pakistan, Philippines, Singapore, Sri Lanka, Taiwan, Thailand and Vietnam, participated in the REAP-BD study, recruiting participants from September to December 2018. Under the direction of Taipei City Hospital, Taipei, Taiwan (receipt number: TCHIRB-10605117-E), every participating center received approval from their own institutional review boards. In order to investigate real clinical practice, simple inclusion criteria of a diagnosis of BD (F31) with the tenth revision of the International Classification of Diseases (ICD-10 $)^{13}$ was applied. To include various clinical settings, 4 universityaffiliated general hospitals, 2 mental hospitals, and 1 veteran health service medical center participated, overall enrolling 350 subjects up to October 8. For this study is still ongoing, we are planned to report the Korean data retrieved from REAP study, whose target number of participants was sufficiently met, as a preliminary report. Demographic and clinical characteristics (employment status, clinical history related to duration of episode, untreated illness duration, rapid cycling, seasonality, psychotropic prescription patterns, and other variables) were investigated. Representative investigators had participated in conferences before the opening of the survey to ensure consistent data collection and evaluation. The data collection was directed by the head center, the Taipei City Psychiatric Center, Taipei, Taiwan. The research protocols and informed consent forms were approved by the institutional review boards of all survey centers under the direction of Taipei City Hospital, Taipei, Taiwan (receipt number: TCHIRB10605117-E). For its coherent evaluation, clarified definition and classification were applied. Psychotropic prescribing patterns were grouped by the Anatomical and Therapeutic Chemical Classification index of the World Health Organization Collaborating Center for Drug Statistics Methodology (with modification of grouping lithium into mood stabilizer (MS) and clonazepam into anxiolytics). ${ }^{14}$ The MS or antipsychotic (AP) monotherapy/polypharmacy group included the MS or AP monotherapy group, MS polypharmacy group (using two or MSs) and the AP polypharmacy group (using two or more APs). A simple polypharmacy group was defined as subjects using one MS and one AP. While the complex polypharmacy group included subjects with three or more of either the MSs or APs. ${ }^{15}$ Body mass index (BMI) calculated as weight (kg) divided by height $(\mathrm{m})^{2}$, classified 4 weight groups; underweight
(<18.50), normal weight (18.50-24.99), overweight (25.00$29.99)$, and obese $(>30) .{ }^{16}$ Subjects with a history of four or more episodes of BD within one year were classified as "history with rapid cycling." ${ }^{17}$ Seasonality patterns are defined as the peaks for manic episodes in spring to summer, depressive episodes in early winter, and mixed episodes in early spring to summer. ${ }^{18}$

Excluding 2 subjects with incomplete information on prescription, 348 subjects were included in our statistical analyses. Clinical and demographic profiles are shown as categorical and continuous variables, respectively. The clinical characteristics were compared among BD patients with MS or AP monotherapy/polypharmacy, simple polypharmacy, and complex polypharmacy. $\chi^{2}$ tests for discrete variables and analyses of covariances for continuous variables were applied for analyses. Categorical variables were presented with frequencies and proportions, whereas continuous variables were presented as mean \pm standard deviation. Statistical significance was set at p $<0.05$ (two-tailed). IBM SPSS 24 (IBM Co., Armonk, NY, USA) was used for statistical analyses.

\section{RESULTS}

Of all subjects, $51.1 \%(n=178)$ were prescribed with simple polypharmacy, followed by $34.2 \%(n=119)$ with complex polypharmacy and $14.7 \%(n=51)$ with MS or AP monotherapy/ polypharmacy. The number of subjects with MS monotherapy $(n=27,7.7 \%)$, AP monotherapy ( $n=14,4.0 \%)$, MS polypharmacy $(n=3,0.9 \%)$ and AP polypharmacy $(n=7,2.0 \%)$ was so small.

As described in Table 1, subjects with MS or AP monotherapy/polypharmacy were significantly older than those with simple or complex polypharmacy, and their frequency of visiting outpatient clinics was higher than that of subjects in the other two groups. A shorter duration of untreated illness $(<6$ months) was mostly high in the simple polypharmacy group, followed by the MS or AP monotherapy/polypharmacy and complex polypharmacy groups. The proportion of manic episodes followed by depressive episodes in the long-term course was the highest in the complex polypharmacy group and smallest in the MS or AP monotherapy/polypharmacy group. The complex polypharmacy group showed shorter duration of current episode with great portion of subjects having less than 1 month of current episode. A BMI of $>25$ is considered as overweight, and both simple polypharmacy and complex polypharmacy groups had a significantly higher BMI than did the MS or AP monotherapy/polypharmacy group. The simple or complex polypharmacy group showed a significantly more overweight status than did the MS or AP monotherapy/polypharmacy group. The MS or AP monotherapy/polypharmacy 


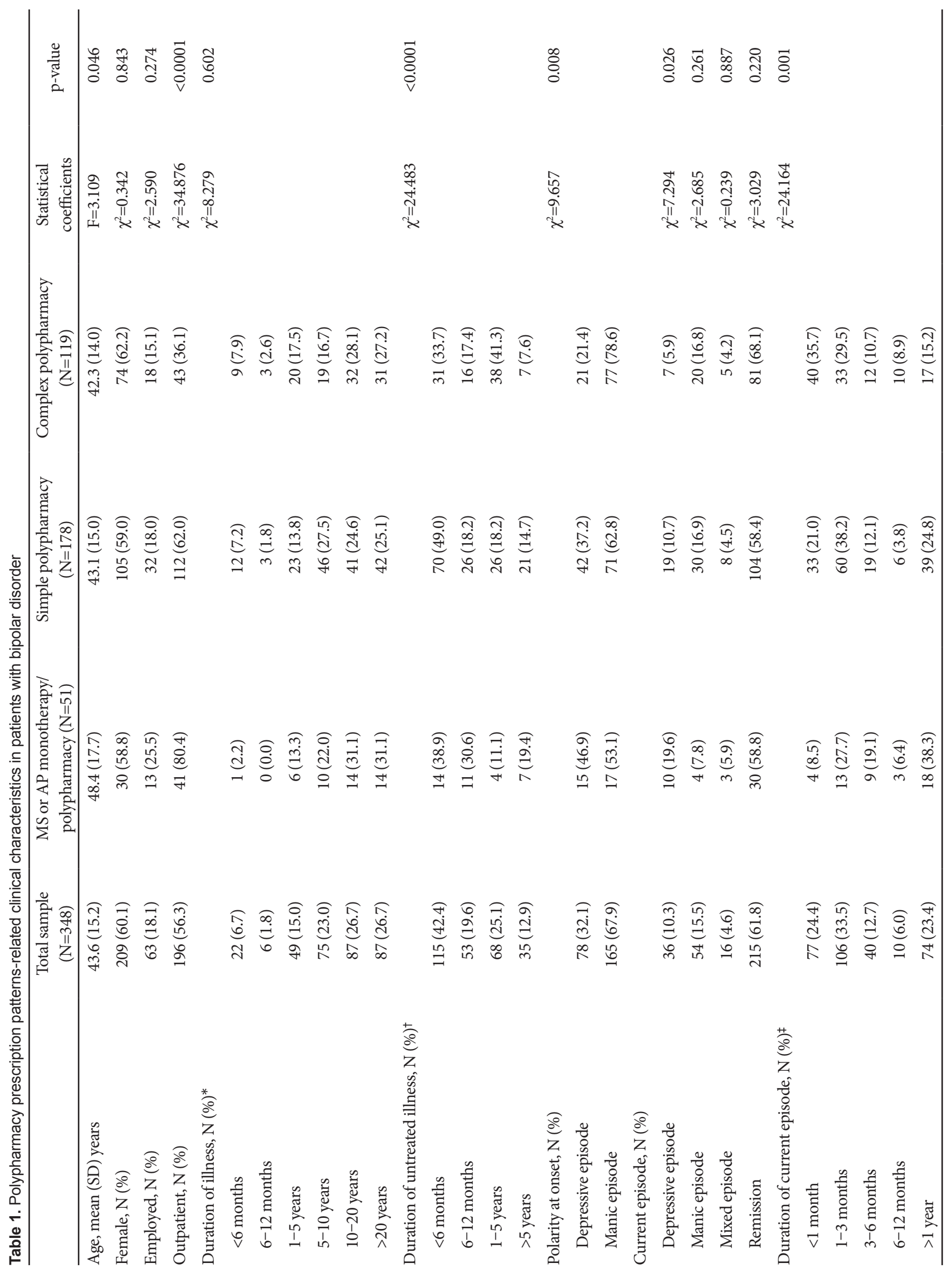




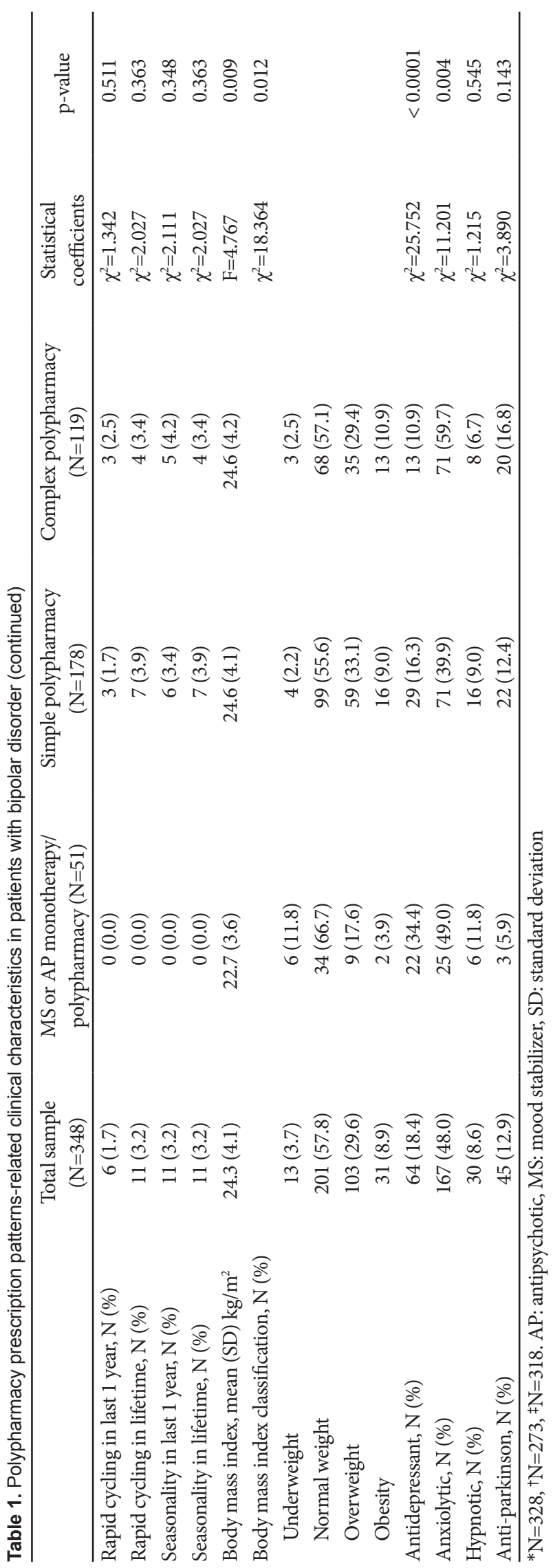

group showed more use of antidepressants than did the other two groups. Even though $10.3 \%$ of subjects were in the currently depressive phase, only $52.8 \%$ of subjects with depressive phase were applied antidepressants. However, anxiolytic prescription was the most common in the complex polypharmacy group, followed by the MS or AP monotherapy/polypharmacy group and then the simple polypharmacy group. There was no significant difference in the proportion of sex, employment status, duration of $\mathrm{BD}$, current episode (depressive episode, manic episode, mixed episode, and remission), history related to rapid cycling, feature related to seasonality and use of hypnotics, and anti-parkinsonian drug among subjects in the 3 discrete prescription groups.

\section{DISCUSSION}

From this study, tendency in simple or complex polypharmacy showed characteristics with younger age, higher inpatient proportion, larger portion of onset with depressive episode, shorter untreated illness, shorter duration of current episode, more overweight, less antidepressants use, and more anxiolytics use than simple polypharmacy.

Old age often makes subjects prone to side effects, an important factor considered when deciding upon prescriptions, ${ }^{19}$ thus explaining why polypharmacy at a younger age may be more common.

Simple or complex polypharmacy, both represent types of combination therapy and may be preferred to MS or AP monotherapy in patients with severe $\mathrm{BD}$, due to better efficacy, with approximately $20 \%$ more patients responding to combination therapy. ${ }^{20,21}$ Subjects with inpatient settings can be interpreted as those having more severe symptoms. A shorter duration of untreated illness could represent a higher need for medical aid, suggesting a more serious clinical situation. A shorter duration of current illness also could be interpreted as need of quick treatment, which can be related to severe disability. In terms of long-term course, the onset of manic episode been associated with a higher number of hospitalizations, suicide attempts, and episodes with psychotic symptoms. ${ }^{22,23}$ Moreover, comorbid anxiety is known to decrease the response to MSs, and as comorbid anxiety disorder or distress is often reported in $\mathrm{BD}$ patients, this may be a cause for increasing polypharmacy. ${ }^{24,25}$ Antidepressant use in our study had different finding with previous report, which observed increased antidepressant prescription in subjects with polypharmacy, most frequently prescribed with escitalopram in subjects with comorbid anxiety. ${ }^{26}$ Meanwhile, the fewer antidepressant prescriptions in the polypharmacy group in this study could be explained by the sedating effect of the antidepressant trazodone, which also can be explained by less frequent prescrip- 
tion in depressive subjects. More subjects with overweight in polypharmacy group was in line with recent report, which showed association with BD state and elevated BMI both impact hippocampal concentration of neurochemicals relevant to $\mathrm{BD} .{ }^{27}$ Careful interpretation on overweight observed in polypharmacy subjects is needed because our study has a crosssectional design, and results are difficult to be explained by causality. However, it is common for patients with $\mathrm{BD}$ to be overweight or obese, which requires regular monitoring on weight changes. ${ }^{28,29}$

This study had several limitations. First, the REAP-BD is not a typical epidemiological survey, therefore it needs careful interpretation when generalizing. Second, the application of objective scales for clinical evaluation and psychiatric comorbidity were not assessed, meaning there was a lack of an overview of functional status. Third, despite the involvement in conferences, variations in clinical evaluation often occur between different researchers.

However, even with these limitations, we showed a high proportion of polypharmacy in $\mathrm{BD}$ from the Korean data of the REAP-BD study and discussed clinical characteristics associated with polypharmacy. These clinical characteristics suggest a more severe state of $\mathrm{BD}$ are associated with polypharmacy, findings which could offer further perspectives for future research tailored for individual state. ${ }^{30}$

\section{Acknowledgments}

This work was supported by the 2018 Inje University Research Grant.

\section{Conflicts of Interest}

The authors have no potential conflicts of interest to disclose.

\section{Author Contributions}

Conceptualization: Park S-C, Lin S-K, Tan CH, Shinfuku N, Park YC. Data curation: Park S-C, Kim K, Yang H, Na E, Lee H, Jang O-J, Yoon H-J, Oh HS, Ham B-J, Park YC. Funding acquisition: Park S-C. Investigation: Park S-C, Kim K, Yang H, Na E, Lee H, Jang O-J, Yoon H-J, Oh HS, Ham B-J, Park YC. Methodology: Park S-C, Lin S-K, Tan CH, Shinfuku N, Park YC. Project administration: Park S-C, Lin S-K, Tan CH, Shinfuku N, Park YC. Supervision: Lin S-K, Tan CH, Shinfuku N, Park YC. Writing-original draft: Kim K. Writing - review \& editing: Kim K, Park S-C, Park YC.

\section{ORCID iDs}

$\begin{array}{ll}\text { Seon-Cheol Park } & \text { https://orcid.org/0000-0003-3691-4624 } \\ \text { Kiwon Kim } & \text { https://orcid.org/0000-0001-7594-0142 } \\ \text { Hyunju Yang } & \text { https://orcid.org/0000-0003-0027-2834 } \\ \text { Euihyeon Na } & \text { https://orcid.org/0000-0001-8657-8855 } \\ \text { Hoseon Lee } & \text { https://orcid.org/0000-0002-4513-4833 } \\ \text { Ok-Jin Jang } & \text { https://orcid.org/0000-0002-6272-7825 } \\ \text { Hyung-Jun Yoon } & \text { https://orcid.org/0000-0003-3087-8853 } \\ \text { Hong Seok Oh } & \text { https://orcid.org/0000-0002-3071-3760 } \\ \text { Byung-Joo Ham } & \text { https://orcid.org/0000-0002-0108-2058 } \\ \text { Shih-Ku Lin } & \text { https://orcid.org/0000-0002-5123-0389 } \\ \text { Chay Hoon Tan } & \text { https://orcid.org/0000-0002-6399-0668 } \\ \text { Naotaka Shinfuku } & \text { https://orcid.org/0000-0002-7390-9077 } \\ \text { Yong Chon Park } & \text { https://orcid.org/0000-0002-3019-5748 }\end{array}$

\section{REFERENCES}

1. Global Burden of Disease Study 2013 Collaborators. Global, regional, and national incidence, prevalence, and years lived with disability for 301 acute and chronic diseases and injuries in 188 countries, 1990-2013: a systematic analysis for the Global Burden of Disease Study 2013. Lancet 2015;386:743-800.

2. Crump C, Sundquist K, Winkleby MA, Sundquist J. Comorbidities and mortality in bipolar disorder: a Swedish national cohort study. JAMA Psychiatry 2013;70:931-939.

3. Phillips ML, Kupfer DJ. Bipolar disorder diagnosis: challenges and future directions. Lancet 2013;381:1663-1671.

4. Grande I, Berk M, Birmaher B, Vieta E. Bipolar disorder. Lancet 2016; 387:1561-1572.

5. Fountoulakis KN, Grunze H, Vieta E, Young A, Yatham L, Blier P, et al. The International College of Neuro-Psychopharmacology (CINP) Treatment Guidelines for Bipolar Disorder in Adults (CINP-BD-2017), Part 3: The Clinical Guidelines. Int J Neuropsychopharmacol 2017;20:180195.

6. Yatham LN, Kennedy SH, Parikh SV, Schaffer A, Bond DJ, Frey BN, et al. Canadian Network for Mood and Anxiety Treatments (CANMAT) and International Society for Bipolar Disorders (ISBD) 2018 guidelines for the management of patients with bipolar disorder. Bipolar Disord 2018;20:97-170.

7. Goodwin GM, Haddad PM, Ferrier IN, Aronson JK, Barnes T, Cipriani $\mathrm{A}$, et al. Evidence-based guidelines for treating bipolar disorder: Revised third edition recommendations from the British Association for Psychopharmacology. J Psychopharmacol 2016;30:495-553.

8. Malhi GS, Bassett D, Boyce P, Bryant R, Fitzgerald PB, Fritz K, et al. Royal Australian and New Zealand College of Psychiatrists clinical practice guidelines for mood disorders. Aust N Z J Psychiatry 2015;49: 1087-1206.

9. Puyat JH, Hanley GE, Cunningham CM, Law MR, Wong ST, Sutherland JM, et al. Ethnic disparities in antipsychotic drug use in British Columbia: a cross-sectional retrospective study. Psychiatr Serv 2011;62: 1026-1031.

10. Weymann D, Smolina K, Gladstone EJ, Morgan SG. High-cost users of prescription drugs: a population-based analysis from British Columbia, Canada. Health Serv Res 2017;52:697-719.

11. Greil W, Haberle A, Haueis P, Grohmann R, Russmann S. Pharmacotherapeutic trends in 2231 psychiatric inpatients with bipolar depression from the International AMSP Project between 1994 and 2009. J Affect Disord 2012;136:534-542.

12. Walpoth-Niederwanger M, Kemmler G, Grunze H, Weiss U, Hortnagl C, Strauss R, et al. Treatment patterns in inpatients with bipolar disorder at a psychiatric university hospital over a 9-year period: focus on mood stabilizers. Int Clin Psychopharmacol 2012;27:256-266.

13. World Health Organization. The ICD-10 Classification of Mental and Behavioral Disorders, Clinical Descriptions and Diagnostic Guidelines. Geneva: World Health Organization; 1992.

14. World Health Organization. Anatomical Therapeutic Chemical (ATC) classification system. Available at: https://www.whocc.no/atc/structure_ and_principles/. Accessed Nov 1, 2018.

15. Goldberg JF, Brooks JO 3rd, Kurita K, Hoblyn JC, Ghaemi SN, Perlis $\mathrm{RH}$, et al. Depressive illness burden associated with complex polypharmacy in patients with bipolar disorder: findings from the STEP-BD. J Clin Psychiatry 2009;70:155-162.

16. World Health Organization. Obesity: Preventing and managing the global epidemic (publication WHO/NUT/NCD/98.1) 1997. whqlibdoc. who.int/hq/1998/WHO_NUT_NCD_98.1_(p1-158).pdf. September 30, 2018.

17. Dunner DL, Fieve RR. Clinical factors in lithium carbonate prophylaxis failure. Arch Gen Psychiatry 1974;30:229-233.

18. Fellinger M, Waldhoer T, Konig D, Hinterbuchinger B, Pruckner N, Baumgartner J, et al. Seasonality in bipolar disorder: Effect of sex and 
age. J Affect Disord 2019;243:322-326.

19. Strakowski SM. CANMAT and ISBD 2018 guidelines for the management of patients with bipolar disorder. Bipolar Disord 2018;20:393-394.

20. Ketter TA. Monotherapy versus combined treatment with second-generation antipsychotics in bipolar disorder. J Clin Psychiatry 2008;69 Suppl 5:9-15.

21. Lin D, Mok H, Yatham LN. Polytherapy in bipolar disorder. CNS Drugs 2006;20:29-42.

22. Belizario GO, Silva M, Lafer B. Impact of predominant polarity on longterm outcome in bipolar disorder: A 7-year longitudinal cohort study. J Affect Disord 2018;241:37-40.

23. Carvalho AF, McIntyre RS, Dimelis D, Gonda X, Berk M, Nunes-Neto $\mathrm{PR}$, et al. Predominant polarity as a course specifier for bipolar disorder: a systematic review. J Affect Disord 2014;163:56-64.

24. Henry C, Van den Bulke D, Bellivier F, Etain B, Rouillon F, Leboyer M. Anxiety disorders in 318 bipolar patients: prevalence and impact on illness severity and response to mood stabilizer. J Clin Psychiatry 2003; 64: 331-335.

25. Yapici Eser H, Kacar AS, Kilciksiz CM, Yalcinay-Inan M, Ongur D. Prevalence and associated features of anxiety disorder comorbidity in bipolar disorder: a meta-analysis and meta-regression study. Front Psychiatry 2018;9:229.

26. Yoon W, Shon SH, Hong Y, Joo YH, Lee JS. Antidepressant prescription patterns in bipolar disorder: a nationwide, register-based study in Korea. J Korean Med Sci 2018;33:e290-e300.

27. Bond DJ, Silveira LE, MacMillan EL, Torres IJ, Lang DJ, Su W, et al. Diagnosis and body mass index effects on hippocampal volumes and neurochemistry in bipolar disorder. Transl Psychiatry 2017;7:e1071.

28. Hu C, Torres IJ, Qian H, Wong H, Halli P, Dhanoa T, et al. Trajectories of body mass index change in first episode of mania: 3-year data from the Systematic Treatment Optimization Program for Early Mania (STOP-EM). J Affect Disord 2017;208:291-297.

29. Bauer M, Andreassen OA, Geddes JR, Vedel Kessing L, Lewitzka U, Schulze TG, et al. Areas of uncertainties and unmet needs in bipolar disorders: clinical and research perspectives. Lancet Psychiatry 2018;5: 930-939.

30. Giampaolo P, Silvia D, Ferdinando S, Wilma M, Paolo C, Daniela C. Shortterm psychiatric rehabilitation in major depressive and bipolar disorders: neuropsychological-psychosocial outcomes. Psychiatry Investig 2017;14:8-15. 